\title{
X-PloRat: A Software for Scoring Animal Behavior in Enclosed Spaces
}

\author{
Julian Tejada ${ }^{1}$ \\ Universidade Federal de Sergipe \\ Khallil Taverna Chaim \\ Universidade de São Paulo \\ Silvio Morato \\ Universidade de São Paulo
}

\begin{abstract}
The present technical note introduces the X-PloRat, a software for the scoring of animal location, displacement, and other behavioral properties, in enclosed spaces. The X-PloRat offers a variety of data reports and can be used for training students in behavioral observation and in validating other kinds of scoring procedures.
\end{abstract}

Keywords: software for behavioral scoring, animal behavior, behavioral tests

\section{X-PloRat: Software para o Registro do Comportamento em Espaços Confinados}

\begin{abstract}
RESUMO - A presente nota técnica apresenta o X-PloRat, um software que permite o registro da localização, deslocamento e outras propriedades do comportamento animal em espaços confinados. O X-PloRat oferece uma grande variedade de relatórios e pode ajudar no treinamento de estudantes em observação do comportamento e também na validação de outros tipos de registros.
\end{abstract}

Palavras-chave: software de registro comportamental, comportamento animal, testes comportamentais

Behavior scoring is one of the most important procedures in studies involving enclosed animals. Two broadly used apparatuses for evaluating anxiety-like behaviors in rodents are the round or rectangular open field (OF) and the elevated plus maze (EPM; Handley \& Mithani, 1984; Pawlak, Karrenbauer, Schneider, \& Ho, 2012; Walf \& Frye, 2007; for a review, see Carobrez \& Bertoglio, 2005). Used by many researchers for a variety of purposes, the EPM consists of a platform with two arms surrounded by walls and two open arms intersected perpendicularly at the center resulting in a plus-shaped delimited space, which is elevated $50 \mathrm{~cm}$ from the floor. Usually, the animal behavior is recorded with a video camera and scoring is done afterwards by watching the video and assigning categories for specific behaviors. Such manual scoring requires considerable training before achieving reliable results, besides being time and energy consuming. Therefore, overcoming these hindrances would be extremely helpful.

There are commercially available softwares that allow automatic recording of behavior, some of which are connected to special apparatuses. These, however, are usually expensive and often depend on specific equipment. There are also non-commercial softwares designed to assist in the scoring of behaviors, one of which is the EPMscore (Patel, Seasholtz, \& Patel, 2006).

Another non-commercial software, the X-PloRat, was developed in the laboratory of one of the present authors (SM) to assist in OF and EPM scoring, and has been distributed as freeware to fellow researchers in Brazil and

1 Address for correspondence: Cidade Univiversitária Prof. José Aloísio de Campos, Av. Marechal Rondon, s/n, Jd. Rosa Elze, São Cristóvão, SE, Brasil. CEP: 49100-000.E-mail: jtejada@ups.br, abroad (X-PloRat, version 2005 1.1.0, available for download at http://sites.ffclrp.usp.br/scotty/). The present technical note aims at introducing the X-PloRat for the scientific community.

The X-PloRat allows the user to virtually divide the apparatus' floor into as many squares (or rectangles) as needed to meet research purposes, and to record both (1) the displacements from one section to another and (2) the occurrence of target behaviors, (e.g., vertical exploration, head dipping, rearing, stretch-attend postures and grooming, among others) in one or more specific sections. The timing of these two types of events is also recorded, and the exact moment of occurrence can be retrieved and entered in spreadsheets for analysis.

In order to perform the scoring, the user first films a session with a video camera placed above the center of the apparatus. A grid designed in a transparent plastic sheet is placed on the TV or monitor that will be used for video playback. While playing the video, the EPM floor image on the screen (in the perspective of the video camera) is observed through the grid, designed according to the desired number of squares. For example, in the EPM, the floor image can be divided into five $10-\mathrm{cm}$ squares per arm plus a central square. The software exhibits a representation of the divided maze according to the divisions in the transparent sheet. The user then watches the video in a TV or monitor adjacent to the computer monitor with the software, and records the displacements from one square to another by pressing the arrow keys indicating the direction of the displacement. The square indicating the animal's position turns red, contrasting with the remaining white squares. In addition to the sequence of displacements and location of the rat, the software also allows the recording of any other kind of behavior that may 
be of interest to the researcher. For this feature, the researcher previously defines a behavior and designates an alphanumeric key to it. At video playback, the behavior is recorded by pressing the specified key to indicate the beginning of the behavior and releasing the key to indicate the end of the behavior.

After the scoring session, data reports may provide (1) the frequency of entries into each square and (2) the time spent in each square. In addition, it may also provide (3) the frequency, (4) location and (5) time spent performing other recorded behaviors. Other more sophisticated reports are also available, such as a minute-by-minute or square-by-square analyses, or even a combination of both.

Due to the good acceptance of the X-PloRat by many Brazilian researchers (Curio et al., 2009; Filgueiras, Carvalho-Netto, \& Estanislau, 2014; Meneses, Lopes, Velarde, \& Boaventura, 2011; Rico, Penagos-Gil, Castañeda, \& Corredor, 2016; Serafim, Kishi, Canto-de-Souza, \& Mattioli, 2010, 2013; Soares, Melo, et al., 2013; Soares, Oliveira, et al., 2013), it is vitally important to make available a formal presentation of the software's technical characteristics.

\section{Technical Characteristics}

\section{Experiment Setup}

The X-PloRat software is a Windows ${ }^{\mathrm{TM}}$ application, written in Object Pascal programming language and it runs in almost any Windows version, and with Wine, in the Linux system. It requires $2 \mathrm{MB}$ of hard disk space and $64 \mathrm{MB}$ of RAM memory.

Before beginning to record the information, the experimental conditions must be defined. The user has to enter defining characteristics, such as the type and size of the apparatus, session duration, etc., into the specific fields of the software interface. Should the software be used to analyze video recordings from settings outside labs (such as classrooms or day care centers, clinical offices, sport courts or even bigger animal quarters, like corrals), the same procedures must be followed (i.e., placing a camera high in the center of the setting, using a gridded transparent screen on the TV monitor, etc.). The software comes with a group of preprogrammed mazes, such as for the EPM and the OF (see examples in Figure 1), with different number of subdivisions. For the EPM, the software comes with three different number of subdivision: 3, 5 and 6 by arm (Figure 1 A-C). For the OF there are two subdivisions by default: 16 and 36 (Figure 1 F-G).

The X-Plo-Rat also allows customizing the grid to any square or rectangular area. For example, it is possible to analyze sessions (or reanalyze the same session for confirmation purposes, etc.) using two or three divisions in each arm. Many researchers prefer to analyze this maze by dividing the arms into two sections (instead of five): one composed by the two squares in the extremities and another composed by the remaining three squares next to the central square.

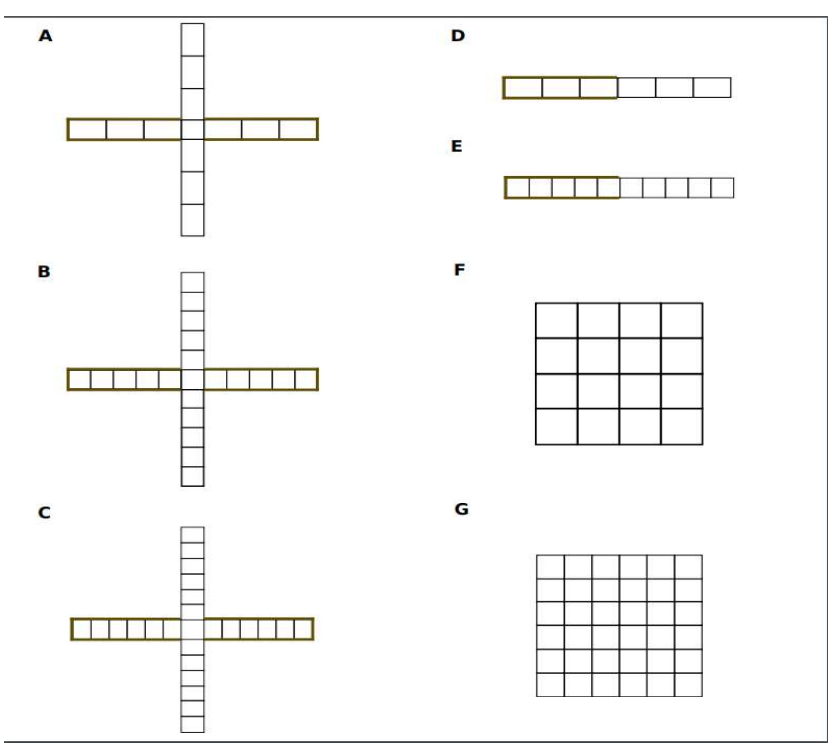

Figure 1. Default maze configurations of the X-PloRat. A-C, elevated plus maze with each arm divided into 3 (A), 5 (B) and 6 sections (C). $\mathrm{D}$ and $\mathrm{E}$, elevated I mazes with each arm divided into 3 (D) and 5 (E) sections. Finally, an open field divided into an area with 4 by $4(\mathrm{~F})$ and 6 by $6(\mathrm{G})$ squares with 16 and 36 squares, respectively.

Once the experimental apparatus is defined, the next step is to specify keys from the keyboard that will be used to represent a specific behavior. X-PloRat allows the configuration of any alphabetic key for recording a specific behavior. Thus, it is possible to specify up to 26 different behaviors by session. Also, it is possible to record nested behaviors, which is when one behavior is followed by another (while maintaining the first) and then returns to the first. For instance, the animal might perform the behavior 'head out', during which it performs the 'head dipping', then 'head dipping' ends, and finally the 'head out' ends. The researcher will press and hold the key assigned to 'head out', then press and hold the key assigned to 'head dipping' for the duration of this behavior, release it when 'head dipping' ends (all this while holding the 'head out' key), and then release the 'head out' key when the episode ends. Finally, the last step is to define a start position, which is the spot the animal will be placed in at the beginning of the session. In the case of the EPM, this is also the spot in which the animal will be placed if it falls out of the maze.

\section{Recording}

As mentioned above, the X-PloRat helps with the manual recording of behaviors while watching the video of a session and displacing the red mark from one square to the next by pressing the arrow keys according to the direction of the displacement (see a screenshot of the X-PloRat running an EPM recording in Figure 2). Simultaneously, it is possible to record other behaviors by pressing and holding previously assigned keys for as long as a specific behavior lasts. 


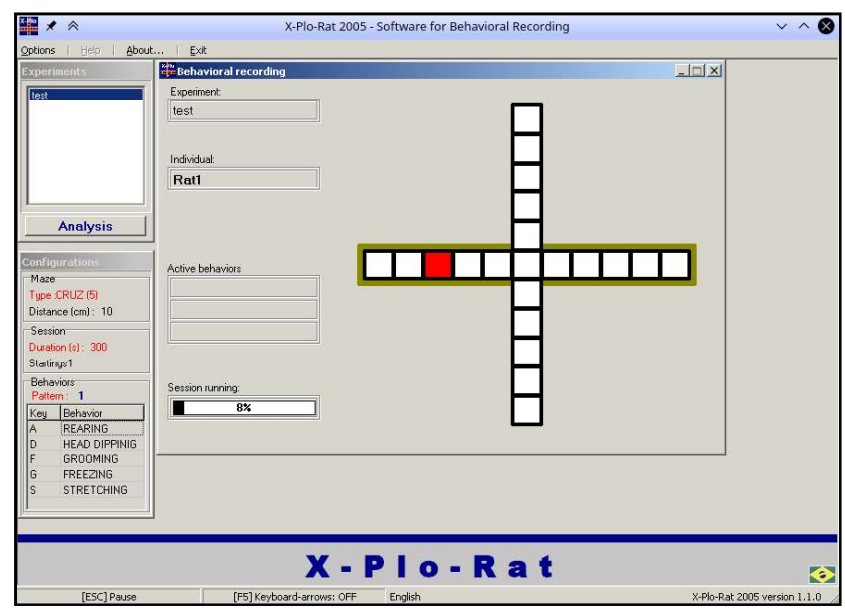

Figure 2. Screenshot of the X-PloRat recording an EPM experiment.

Once the recording is finished, the software saves the data in a text file into the Installation folder. This file contains the recorded information in an intuitive table, which can be used to generate various types of reports.

\section{Analysis}

The software's analysis module allows the recorded information to be retrieved, either grouped by square, by time or both. The two main options available are Whole session and Minute by minute, which, as the names imply, are related to the duration of the session. In the Whole session option, a report of all the events that occurred in the whole session is generated. On the other hand, the Minute by minute option generates reports informing the events that happened in each minute of the session.

Under each of the above options, the software can produce even more refined reports by choosing: Compact, Compact by arm and By squares. The first two are reports specific for the EPM. The Compact retrieval option aggregates the results by open and closed arms. On the other hand, the Compact by arm option aggregates the results by each of the four arms (e.g., the west closed arm, the east closed arm, the north open arm and the south open arm). Finally, the By square option arranges the events of the whole session by each of the squares into which the maze is divided.

All the above options arrange the results in a .txt file format table which can be readily processed by a spreadsheet software. The table contains the frequency and duration of each behavior. The analysis options also allow entering data of several animals in the same file, facilitating the transfer into statistical software.

\section{Further Improvements}

Over the years, users have requested the feature that would allow the visualization of the video with an overlapped image "mask" of the grid, making the animal localization in each square easier. Although this is not presently an out-of-thebox feature, with the advent of more sophisticated operating systems with more powerful compositing window managers (such as the Desktop Window Manager for Windows or Compiz and Kwin for Linux), the implementation of this feature could be possible. For the time being, there are a series of different Windows applications that can be used to change the opacity of the windows that could be used to add a mask to the video image (see www.ghostwindows.com). In some cases, especially when the EPM is used, it may be necessary to rotate the image to fit with the overlapping mask. To do this, we suggest the use of a video player that allows a 360 degree rotation, such as the VLC, an open-source cross-platform video player (http://www.videolan.org/vlc/).

By combining software that controls the opacity/ transparency of windows with software able to rotate and play a video, it is possible to obtain the effect of superimposing the $\mathrm{X}$-PloRat grid to the video and record the behavior by moving the red square over the actual image of the rat, improving the accuracy of the records.

Another limiting aspect of the X-PloRat is the use of a grid (perpendicular lines) to define the apparatus' areas, making its use impractical to record behaviors in circular OF or radial mazes. However, the X-PloRat could be adapted to the circular OF, which is mostly used in pharmacological studies, if the round area is conceived as a square area in which the animal is unable to explore the corners. In other words, because the X-PloRat is a software for manual recording, it may be adapted to other situations than those for which it was planned. For instance, in a situation in which displacement is not of interest, it is possible to define the whole area as a unique square, and record the defined behaviors by using the alphabetic keys.

\section{References}

Carobrez, A. P., \& Bertoglio, L. J. (2005). Ethological and temporal analyses of anxiety-like behavior: The elevated plus-maze model 20 years on. Neuroscience \& Biobehavioral Reviews, 29(8), 1193-1205.

Curio, M., Jacone, H., Perrut, J., Pinto, Â. C., Valdir Filho, F. V., \& Silva, R. C. (2009). Acute effect of Copaifera reticulata Ducke copaiba oil in rats tested in the elevated plus-maze: An ethological analysis. Journal of Pharmacy and Pharmacology, 61(8), 1105-1110.

De Meneses, J. A., Lopes, C. J., Velarde, L. C., \& Boaventura, G. T. (2011). Behavioral analysis of Wistar rats fed with a flaxseed based diet added to an environmental enrichment. Nutricion Hospitalaria, 26(4), 716-721.

Filgueiras, G. B., Carvalho-Netto, E. F., \& Estanislau, C. (2014). Aversion in the elevated plus-maze: role of visual and tactile cues. Behavioural Processes, 107, 106-111.

Handley, S. L., \& Mithani, S. (1984). Effects of alpha-adrenoceptor agonists and antagonists in a maze-exploration model of "fear"-motivated behaviour. Naunyn-Schmiedeberg's Archives of Pharmacology, 327(1), 1-5.

Kishi, M. S. (2009). Efeitos de antagonistas histaminérgicos H1 e H2 sobre a ansiedade e a memória emocional de camundongos (Unpublished doctoral Dissertation). Universidade Federal de São Carlos. Retrieved from http://www.bdtd.ufscar.br/ htdocs/tedeSimplificado/tde_arquivos/4/TDE-2009-0901T161741Z-2366/Publico/2563.pdf 
Patel, P. D., Seasholtz, A. F., \& Patel, P. D. (2006). Computerassisted scoring of the elevated plus maze. BioTechniques, 41(6), 700-704.

Pawlak, C. R., Karrenbauer, B. D., Schneider, P., \& Ho, Y.-J. (2012). The Elevated Plus-Maze Test: Differential psychopharmacology of anxiety-related behavior. Emotion Review, 4(1), 98-115. doi: http://doi.org/10.1177/1754073911421374

Pitta, F. D. (2013). Histamina intra-amídala modula a memória aversiva de camundongos submetidos à esquiva inibitória, mas não à reexposição no LCE (Unpublished master's thesis). Universidade de São Paulo. Retrieved from http://www.teses. usp.br/teses/disponiveis/59/59134/tde-23102013-154130/ en.php

Rico, J. L., Penagos-Gil, M., Castañeda, A. F., \& Corredor, K. (2016). Gerbils exhibit stable open-arms exploration across repeated testing on the elevated plus-maze. Behavioural Processes, 122, 104-109.

Salum, C., Roque-da-Silva, A. C., \& Morato, S. (2003). Conflict as a determinant of rat behavior in three types of elevated plusmaze. Behavioural Processes, 63(2), 87-93.

Serafim, K. R., Kishi, M., Canto-de-Souza, A., \& Mattioli, R. (2010). L-histidine provokes a state-dependent memory retrieval deficit in mice re-exposed to the elevated plus-maze. Brazilian Journal of Medical and Biological Research, 43(1), 100-106.
Serafim, K. R., Kishi, M. S., Canto-de-Souza, A., \& Mattioli, R. (2013). H1 but not $\mathrm{H} 2$ histamine antagonist receptors mediate anxiety-related behaviors and emotional memory deficit in mice subjected to elevated plus-maze testing. Brazilian Journal of Medical and Biological Research, 46(5), 440-446.

Soares, J. K., de Melo, A. P., Medeiros, M. C., Queiroga, R. C., Bomfim, M. A., Santiago, E. C., \& Guedes, R. C. (2013). Anxiety behavior is reduced, and physical growth is improved in the progeny of rat dams that consumed lipids from goat milk: An elevated plus maze analysis. Neuroscience Letters, 552, 25-29.

Soares, R. O., Oliveira, L. M., Marchini, J. S., Antunes-Rodrigues, J., Elias, L. L., \& Almeida, S. S. (2013). Effects of early protein malnutrition and environmental stimulation on behavioral and biochemical parameters in rats submitted to the elevated plusmaze test. Nutritional Neuroscience, 16(3), 104-112.

Walf, A. A., \& Frye, C. A. (2007). The use of the elevated plus maze as an assay of anxiety-related behavior in rodents. Nature Protocols, 2(2), 322-328.

Recebido em 21.03.2016

Primeira decisão editorial em 01.12.2016

Versão final em 21.01.2017 Aceito em 23.03.2017 